Research Article

\title{
Vibration Characteristics and Power Flow Analyses of a Ship Propulsion Shafting System with General Support and Thrust Loading
}

\author{
Deshui Xu $\mathbb{D}^{\mathbb{D}}$, Jingtao Du $\mathbb{D}^{\mathrm{D}}$, and Chuan Tian \\ College of Power and Energy Engineering, Harbin Engineering University, Harbin 150001, China \\ Correspondence should be addressed to Jingtao Du; dujingtao@hrbeu.edu.cn
}

Received 1 December 2019; Accepted 25 February 2020; Published 13 June 2020

Academic Editor: Toshiaki Natsuki

Copyright @ 2020 Deshui Xu et al. This is an open access article distributed under the Creative Commons Attribution License, which permits unrestricted use, distribution, and reproduction in any medium, provided the original work is properly cited.

\begin{abstract}
In this paper, flexural vibration and power flow transmission of a ship propulsion shafting structure are analyzed via energy principle description in conjunction with Rayleigh-Ritz procedure, in which the shafting vibration displacement is constructed as a superposition of Fourier series and boundary-smoothing supplementary functions. Effect of the distributed bearing support and thrust loading of propulsion shafting system is considered in terms of potential energy of system Lagrangian. Numerical examples are presented to demonstrate the reliability and effectiveness of the established model by comparing results with those from finite element method. Results show that the current model can deal with the vibration analysis of ship propulsion shafting with thrust loading and distributed bearing very well. Influence of boundary restraints, stiffness of distributed bearings, and thrust loading on vibration characteristics of ship shafting system is studied and addressed. Numerical study on power flow analysis is also conducted to investigate the characteristics of vibrational energy transmission in such practical structure. Results show that the stiffness of spatial bearing support has significant influence on vibrational energy transmission and thrust force will greatly affect the total input power into such structure.
\end{abstract}

\section{Introduction}

Propulsion shafting is an important component of the marine power system, which converts the torque generated by the main engine into the ship propulsion force. Extensive study and experimental test have been performed on its torsional vibration. Obviously, a good understanding on its dynamic characteristics will be of fundamental significance for the efficient design and operation of such complex system. Vibration characteristics have a significant effect on the energy transmission of propulsion shafting. For this reason, transverse vibration and energy transmission through the propulsion shafting system have been studied extensively for many decades $[1,2]$.

Flexural vibration of ship shafting system can be studied by transfer matrix method, finite element method, and experimental measurement [3,4]. For the small propeller/ shaft mass ratio, forward and reverse frequencies coalesce in one value, which may be determined from the vibration analysis of a nonrotating shaft model [5]. Zhu et al. [6] used a cantilever beam theory to establish the finite element model of a large ship and the results show that the attached water weight of propeller and the gyroscopic moment have great influence on natural frequency of flexural vibration. With the emergence of extremely large ships such as VLCC, the propulsion shafting becomes more and more complex. Then, the stepped beam model is widely used in the transverse vibration analysis, and the propeller is simplified as a mass block applied on one end of the model $[7,8]$. Study of the torsional vibration and its coupled vibration analysis such as bending-longitudinal and bending-torsional coupled vibrations of propulsion shafting has attracted a lot of research attention from many researchers [9-11].

Although a lot of investigation has been carried out on the vibration characteristics of ship propulsion shafting, most of the bearing support is mainly simplified as point 
support $[12,13]$. With the aim to achieve a more accurate treatment of bearing support, vibration characteristics modeling of a partially supported beam was carried out by Eisenbegrer et al. [14] and Kushner et al. [15]. By transforming the partial support into an equivalent external load, Motaghian et al. [16] examined the vibration behavior of a beam structure with various boundaries. Moreover, considering a beam structure under axial load, Wu and Chang [17] derived the exact natural frequencies and their associated mode shapes for an axial-loaded multistepped Timoshenko beam carrying any number of various concentrated elements by using the continuous-mass transfer matrix (CTMM). Kim [18] studied the vibration behavior and stability of an infinite Bernoulli-Euler beam resting on elastic foundation under uniform axial load. Borbón and Ambrosini [19] investigated the influence of axial load on natural frequencies of thin-walled beam with classical boundary condition. Numerical and experimental studies about modal frequencies of axially loaded cantilever beam are carried out by $\mathrm{Li}$ et al. [20]. Although the partially supported beam was investigated, the distributed support bearings are still not employed in practical propulsion shafting analysis.

The propulsion shafting will suffer extra excitation force caused by the propeller and unbalanced excitation of shafting itself which will stimulate the system vibration and energy transmission to the hull structure [21]. Vibrational energy is mainly transmitted into the ship hull through the supporting bearings, and power flow analysis is conducted to investigate the dynamic characteristics of vibrational energy transmission in such system [22, 23]. Feng et al. [24] proposed a substructure approach to analyze the vibration transmission in a complex coupled beam-cylindrical shell system. Dylejko et al. [25] established the propeller-shafting coupled model using a modular transmission matrix description to study the force transmissibility and power transmission as well as the optimum design of resonance changer. In the existing studies, although the effect of transverse force on vibration and energy transmission has been investigated, the influence of thrust force has not been sufficiently considered.

Motivated by the current limitation on these aspects in literature, we aim in this paper to establish a more general model for the vibration analysis of propulsion shafting system with multiple bearings and thrust force generated by propeller. Stepped beam model is employed to stimulate the shafting structure considering the partially distributed bearing and thrust load. In order to make the displacement expansion sufficiently smooth in the entire solving region, Fourier series supplemented with boundary smoothed auxiliary terms is employed for admissible function construction. All the unknown coefficients are determined in conjunction with energy formulation of the propulsion shafting system through Rayleigh-Ritz procedure. Numerical examples are presented to validate the proposed model through the comparison with those results calculated from other approaches. Based on the model established, influence of some important factors, including boundary restraints, bearing stiffness, and thrust loading, on the vibration characteristics of propulsion shafting structure is studied and addressed. Then, power flow analysis is conducted to investigate the vibrational energy transmission behavior in such propulsion shafting system.

\section{Theoretical Formulations}

2.1. Model Description. For a practical shafting system shown in Figure 1, it usually consists of the transmission shaft, bearing and other accessories, and so on. Ship shafting structure usually contains the stern shaft, intermediate shaft, and three supporting bearings. In order to analyze the flexural vibration of propulsion shafting in its original structure, the stepped beam model with concentrated mass representing propeller effect with free boundary condition in Figure 2 is used, which is simplified from an actual ship propulsion shafting system as presented in Figure 3 . Figure 2(a) is a stepped beam model of a shafting structure with three partial support bearings $[14,15]$, including a centralized mass on free end and eight beam members, in which $3^{\#}$ beam has a variable cross section. The length of stern shaft extends to the center of the propeller properly and then propeller can be treated as a centralized mass located on the left side. $k_{1}, k_{2}$, and $k_{3}$ represent the stiffnesses of stern rear bearing, stern front bearing, and intermediate bearing, respectively. Figure 2(b) is the coupling interface of two beam sections, in which $K_{C R}$ and $k_{C T}$ are the rotational and translational spring stiffnesses of the coupling interface. $K_{R}$ and $k_{T}$ are the rotational and translational spring stiffnesses for both ends of beams which can simulate the arbitrary boundary conditions by adjusting the stiffness coefficients, accordingly. For the propulsion shafting illustrated in Figure 2, only the $K_{R}$ and $k_{T}$ of $8^{\#}$ beam on the right side should be considered. Thrust force $F$ generated by propeller is introduced at left end of the current model. Specific parameters of the propulsion shafting model are given in Table 1 . The modulus of elasticity $E$ is $2.1 \times 10^{11} \mathrm{~Pa}$ and the density $\rho$ is $7800 \mathrm{~kg} / \mathrm{m}^{3}$.

For the harmonic oscillation, transverse vibration of each beam element will be assumed as $W(x, t)=w(x) e^{j \omega t}$, where $w(x)$ is the transverse vibration displacement function and $\mathrm{e}^{j \omega t}$ is the time factor. Differential continuity of the constructed displacement field function has significant effect on the final convergence and accuracy.

In vibration theory, it is normal to assume the displacement into Fourier series for the vibration analysis of an elastic rod/beam structure, namely, [26].

$$
w(x)=\sum_{n=0}^{\infty} a_{n} \cos \left(\lambda_{n} x\right),
$$

with its first-order derivative at both ends

$$
\begin{aligned}
& \left.\frac{\partial w(x)}{\partial x}\right|_{x=0}=-\sum_{n=0}^{\infty} a_{n} \lambda_{n} \sin \left(\lambda_{n} 0\right)=0, \\
& \left.\frac{\partial w(x)}{\partial x}\right|_{x=L}=-\sum_{n=0}^{\infty} a_{n} \lambda_{n} \sin \left(\lambda_{n} L\right)=0 .
\end{aligned}
$$




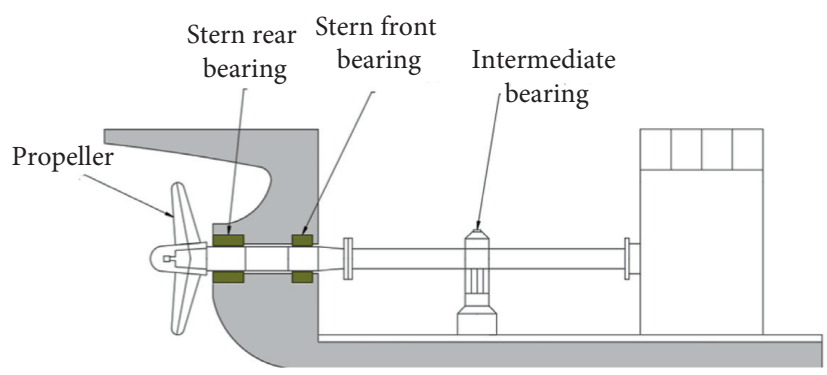

FIgURE 1: An illustrative model of a ship propulsion shafting system.

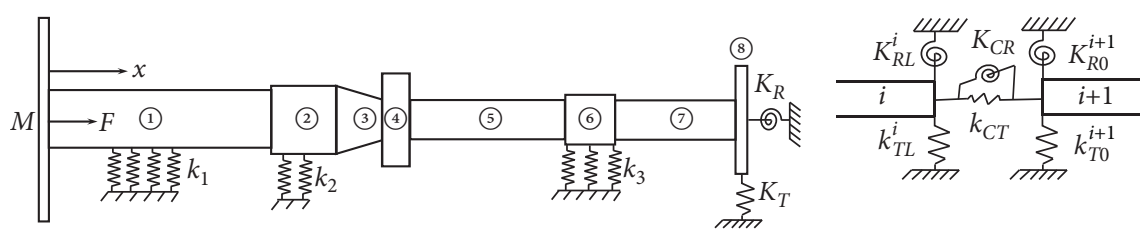

(a)

(b)

Figure 2: (a) The simplified stepped beam model of the propulsion shafting structure; (b) the coupling interface of two beam sections.

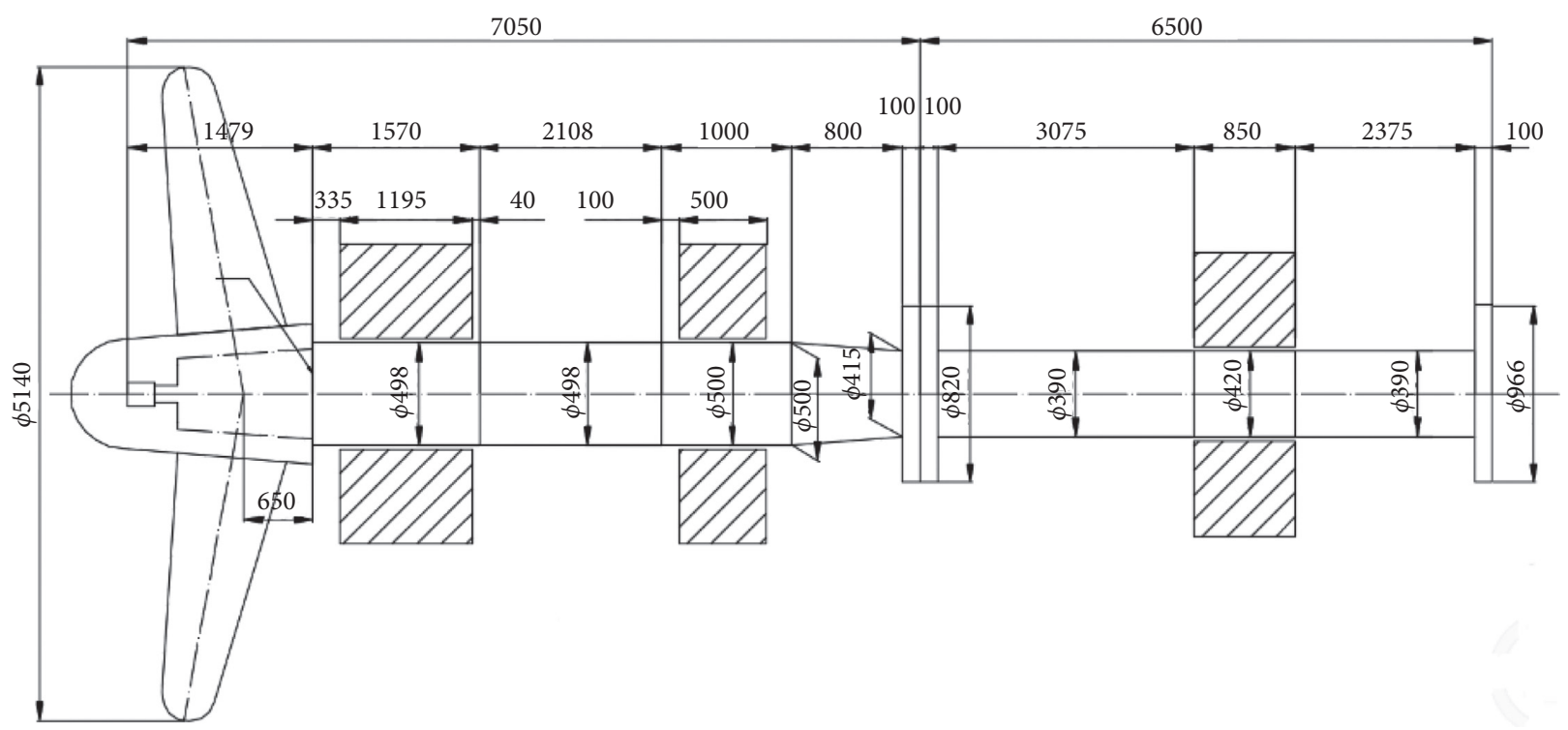

FIGURE 3: The diagram of a ship propulsion shafting.

We can find that the first-order differentials at both ends are always zero, which can just be used for certain classical boundary condition. For the general elastic restraints, it will not be always zero physically; namely, the standard Fourier cosine or sine series does not possess the ability for the displacement expression of propulsion shafting structure with such elastic boundary conditions. In order to overcome the differential discontinuity of classical Fourier series, the supplementary functions are introduced to remove the jump points at both elastic ends.

A modified version of Fourier series is employed to deal with this issue, in which the additional polynomials are introduced to the standard Fourier series to remove all the discontinuities associated with the spatial differentiation of the displacement field functions. Flexural vibrational displacement function of these beam elements will be expanded as follows and the detailed polynomial expressions can be obtained in [27].

$$
\begin{aligned}
w(x)= & \sum_{n=0}^{\infty} a_{n} \cos \left(\frac{n \pi}{L} x\right)+b_{1} \xi_{1}(x)+b_{2} \xi_{2}(x) \\
& +b_{3} \xi_{3}(x)+b_{4} \xi_{4}(x),
\end{aligned}
$$


TABLE 1: The specific parameters of the propulsion shafting.

\begin{tabular}{lcccc}
\hline Category & Mass $(\mathrm{kg})$ & Length $(\mathrm{mm})$ & Diameter $(\mathrm{mm})$ & Equivalent stiffness $(\mathrm{N} / \mathrm{m})$ \\
\hline$M$ & 10500 & - & 498 & - \\
$(1)$ & - & 4328 & 500 & - \\
(2) & - & 1000 & $(500,415)$ & - \\
$(3)$ & - & 800 & 820 & - \\
(4) & - & 200 & 390 & - \\
(5) & - & 3075 & 420 & - \\
(6) & - & 850 & 390 & - \\
(7) & - & 2375 & 966 & - \\
(8) & - & 100 & & $5 \mathrm{e} 8$ \\
$k_{1}$ & - & 1195 & & $1 \mathrm{e} 9$ \\
$k_{2}$ & - & 500 & & $1 \mathrm{e} 9$ \\
$k_{3}$ & - & 850 & & \\
\hline
\end{tabular}

in which $n$ is the integers, $L$ is the length of each beam element, and $a_{n}$ and $b_{i}$ are the unknown coefficients. The supplementary functions are defined as

$$
\begin{aligned}
& \zeta_{1}(x)=\frac{9 L}{4 \pi} \sin \left(\frac{\pi x}{2 L}\right)-\frac{L}{12 \pi} \sin \left(\frac{3 \pi x}{2 L}\right), \\
& \zeta_{2}(x)=-\frac{9 L}{4 \pi} \cos \left(\frac{\pi x}{2 L}\right)-\frac{L}{12 \pi} \cos \left(\frac{3 \pi x}{2 L}\right), \\
& \zeta_{3}(x)=\frac{L^{3}}{\pi^{3}} \sin \left(\frac{\pi x}{2 L}\right)-\frac{L^{3}}{3 \pi^{3}} \sin \left(\frac{3 \pi x}{2 L}\right), \\
& \zeta_{4}(x)=-\frac{L^{3}}{\pi^{3}} \cos \left(\frac{\pi x}{2 L}\right)-\frac{L^{3}}{3 \pi^{3}} \cos \left(\frac{3 \pi x}{2 L}\right) .
\end{aligned}
$$

2.2. Energy Formulation and Solution Procedure. In most of the existing studies, vibration characteristics and power flow analysis of propulsion shafting are mainly focused on the classical boundary conditions and point support conditions. In order to analyze vibration behavior of the established model in Figure 2(a), a unified solution will be proposed from the viewpoint of energy principle, which will bring the benefit to account for any parametric variation of the propulsion system such as boundary restraints, bearing supports, and thrust force. Lagrangian function for the transverse vibration of current model with general boundary and bearing support conditions subjected to thrust loading can be written as

$$
\begin{aligned}
L=V-T-W= & \sum_{i=1}^{8} V_{i}+\sum_{i=1}^{7} V_{c p}^{i, i+1}+\sum_{i=1,2,6} V_{s p i} \\
& -\sum_{i=1}^{8} T_{i}-T_{\text {mass }}-W,
\end{aligned}
$$

where $L$ is the system Lagrangian, $V$ and $T$ are the total potential and kinetic energies, $V_{i}$ is the potential energy associated with the $i^{\text {th }}$ beam member, $V_{c p}^{i, i+1}$ is the potential energy stored in the interface coupling springs between $i^{\text {th }}$ and $(i+1)^{\text {th }}$ beam member, $V_{s p i}$ is the potential energy stored in the bearing support of the $1^{\#}, 2^{\#}, 6^{\#}$ beams, $T_{i}$ is the kinetic energy due to the $i^{\text {th }}$ vibrating beam, and $T_{\text {mass }}$ is the kinetic energy of the propeller. A separate coordinated system will be used for each beam section with the origin located on the left.

For the $i^{\text {th }}$ beam section member with elastically restrained edges, its potential energy $V_{i}$ is

$$
\begin{aligned}
V_{i}= & \frac{1}{2} \int_{0}^{L} E_{i} I_{i}(x)\left[\frac{\partial^{2} w_{i}(x)}{\partial x^{2}}\right]^{2} \mathrm{~d} x \\
& +\left.\frac{1}{2} k_{T 0}^{i} w_{i}^{2}(x)\right|_{x=0}+\left.\frac{1}{2} K_{R 0}^{i}\left[\frac{\partial w_{i}(x)}{\partial x}\right]^{2}\right|_{x=0} \\
& +\left.\frac{1}{2} k_{T L}^{i} w_{i}^{2}(x)\right|_{x=L}+\left.\frac{1}{2} K_{R L}^{i}\left[\frac{\partial w_{i}(x)}{\partial x}\right]^{2}\right|_{x=L},
\end{aligned}
$$

where $w(x)$ is the transverse vibration displacement function, $E_{i}$ and $I_{i}(x)$ are modulus of elasticity and moment of inertia of the $i^{\text {th }}$ beam member which will be constant for the uniform beam section, and $k_{T 0}$ and $K_{R 0}$ are, respectively, the stiffness coefficients for the translational and rotational restraining springs at the end $x=0$, and similar meaning can be deduced for the right end of $x=L$ for each beam section.

For the uniform beam, the moment of inertia $I_{i}(x)$ will be constant. If the beam member has a variable cross section, the integration in equation (6) will become more complicated. In order to treat the integration for different cross section uniformity, moment of inertia $I_{i}(x)$ will be also expanded into the cosine Fourier series, and the corresponding expansion formulations are as follows:

$$
\begin{aligned}
I_{i}(x) & =I_{0} f_{1}(x)=I_{0}\left(\frac{d_{0}}{2}+\sum_{m=1}^{\infty} d_{m} \cos \lambda_{m} x\right) \\
& =I_{0} \sum_{m=0}^{\infty} d_{m} \cos \lambda_{m} x, \\
d_{m} & = \begin{cases}\frac{1}{2} \frac{2}{L} \int_{0}^{L} f_{1}(x) \mathrm{d} x, & m=0, \\
\frac{2}{L} \int_{0}^{L} f_{1}(x) \cos \frac{m \pi}{L} x \mathrm{~d} x, & m \neq 0,\end{cases}
\end{aligned}
$$

in which $\lambda_{m}=m \pi / L, m$ is the Fourier series items, and shape function $f_{1}(x)$ can be arbitrary form. 
Since the propulsion shafting structure is analyzed on the basis of the stepped beam model, the mechanical coupling springs between each beam section must be taken into account. The potential energy associated with the coupling springs between the handshake interfaces (Figure 2(b)) can be written as

$$
\begin{aligned}
V_{c p i(i+1)}^{i, i+1}= & \frac{1}{2} k_{C T}\left(\left.w_{i}\right|_{x_{i}=L_{i}}-\left.w_{i+1}\right|_{x_{i+1}=0}\right)^{2} \\
& +\frac{1}{2} K_{C R}\left(\left.\frac{\partial w_{i}}{\partial x}\right|_{x_{i}=L_{i}}-\left.\frac{\partial w_{i+1}}{\partial x}\right|_{x_{i+1}=0}\right)^{2},
\end{aligned}
$$

where $k_{C T}$ and $K_{C R}$ are, respectively, the translational and rotational coupling spring stiffnesses distributed across the interface between the $i^{\text {th }}$ and $(i+1)^{\text {th }}$ beam members and $w_{i}$ and $w_{i+1}$ are the translational displacement of the $i^{\text {th }}$ and $(i+1)^{\text {th }}$ beam members.

For such three supporting bearings, the partial supports are considered in this work. The corresponding potential energy of these partial supports will be described as

$$
V_{s p i}=\sum_{i=1,2,6} \frac{1}{2} \int_{x_{i 1}}^{x_{i 2}} k_{i}(x) w_{i}^{2} \mathrm{~d} x,
$$

in which $x_{i 1}$ and $x_{i 2}$ represent the distribution region of these three partial supports. When $x_{i 1}$ is equal to $x_{i 2}$, such partial support will be simplified as a traditional point support. Then, the partial and full supports for propulsion shafting system can be readily modelled in this unified pattern. $k_{i}(x)$ is the supporting stiffness distribution function which can take arbitrary functions or constant one.

When the thrust force is applied at the left end of this model, there will be an equal force on any of its cross sections of the propulsion shaft. Introduction of extra axial loading will affect the differential equation in equation (10) for the single beam structure $[28,29]$, in which the force will affect the shear force strongly and has smaller effect for the bending moment.

$$
\frac{\partial^{2}}{\partial x^{2}}\left(E I \frac{\partial^{2} W(x, t)}{\partial x^{2}}+F W(x, t)\right)+\rho A \frac{\partial^{2} W(x, t)}{\partial t^{2}}+k(x) W(x, t)=0 .
$$

Its relevant potential energy can be written as

$$
V_{F}=\frac{1}{2} \int_{0}^{L} F\left(\frac{\partial w}{\partial x}\right)^{2} \mathrm{~d} x
$$

The total kinetic energy of the $i^{\text {th }}$ beam structure is

$$
T_{i}=\frac{1}{2} \omega^{2} \int_{0}^{L} \rho_{i} S_{i}(x) w_{i}^{2}(x) \mathrm{d} x,
$$

where $\omega$ is the radian frequency in $\mathrm{rad} / \mathrm{s}$ and $\rho_{i}$ and $S_{i}(x)$ are, respectively, the mass density and cross section area which will be constant for the uniform beam section. Variable cross section $S_{i}(x)$ of the $3^{\text {rd }}$ beam model will be also expanded into the Fourier cosine series, namely,

$$
\begin{aligned}
S_{i}(x) & =S_{0} f_{1}(x)=S_{0}\left(\frac{c_{0}}{2}+\sum_{m=1}^{\infty} c_{m} \cos \lambda_{m} x\right) \\
& =S_{0} \sum_{m=0}^{\infty} c_{m} \cos \lambda_{m} x, \\
c_{m} & = \begin{cases}\frac{1}{2} \frac{2}{L} \int_{0}^{L} f_{1}(x) \mathrm{d} x, & m=0, \\
\frac{2}{L} \int_{0}^{L} f_{1}(x) \cos \frac{m \pi}{L} x \mathrm{~d} x, & m \neq 0 .\end{cases}
\end{aligned}
$$

Kinetic energy of the propeller is

$$
T_{\text {mass }}=\frac{1}{2} \omega^{2} M w^{2}\left(x_{0}\right),
$$

where $M$ and $x_{0}$ are the mass and location of the propeller.

Once the system Lagrangian is formulated, substituting the constructed admissible function equation (3) into the Lagrangian equation (5), minimizing it with respect to all the unknown expansion coefficients, and truncating the Fourier series into a finite number $n=N$ in which $N$ is 45 in the following analysis and the result is in convergence, the system characteristic equation in matrix form will be then obtained. During the process of minimization, one will find that the positive term (potential energy term) in Lagrangian equation (5) contributes to the system stiffness matrix, and the negative term (kinetic energy term) devotes to the mass matrix accordingly. The coupling potential energy in equation (8) illustrates the interrelation of two adjacent beam sections. Four stiffness matrices can be obtained from such minimizing operation of equation (8), which can be written as

$$
\left[\begin{array}{ll}
\mathbf{K}_{c p i(i+1)}^{i, i} & \mathbf{K}_{c p i(i+1)}^{i, i+1} \\
\mathbf{K}_{c p i(i+1)}^{i+1, i} & \mathbf{K}_{c p i(i+1)}^{i+1, i+1}
\end{array}\right]_{2(N+5) \times 2(N+5)},
$$

in which $\mathbf{K}$ means a $(N+5)$-dimensional square stiffness matrix as $N$ is calculated from zero and there are four supplementary functions in equation (6) and the same subscript is used as in equation (8).

Then, the coupling stiffness matrix $\mathbf{K}_{c p}$ obtained from equation (8) is given as follows:

$$
\mathbf{K}_{c p}=\left[\begin{array}{ccccc}
\mathbf{K}_{c p 12}^{1,1} & \mathbf{K}_{c p 12}^{1,2} & & & \\
\mathbf{K}_{c p 12}^{2,1} & \mathbf{K}_{c p 12}^{2,2}+\mathbf{K}_{c p 23}^{2,2} & \ddots & & \\
& \mathbf{K}_{c p 23}^{3,2} & \ddots & \mathbf{K}_{c p 67}^{6,7} & \\
& & \ddots & \mathbf{K}_{c p 67}^{7,7}+\mathbf{K}_{c p 78}^{7,7} & \mathbf{K}_{c p 78}^{7,8} \\
& & & \mathbf{K}_{c p 78}^{8,7} & \mathbf{K}_{c p 78}^{8,8}
\end{array}\right]_{8(N+5) \times 8(N+5)}
$$

Similarly, the corresponding stiffness matrix and mass matrix can be deduced from the above equations. Then, the whole stiffness matrix $\mathbf{K}$ and mass matrix $\mathbf{M}$ of the 
propulsion shafting system with general boundary and bearing support conditions can be given as

$$
\begin{aligned}
& \mathbf{K}=\mathbf{K}_{\text {rod }}+\mathbf{K}_{c p}+\mathbf{K}_{s p}+\mathbf{K}_{F}, \\
& \mathbf{M}=\mathbf{M}_{\text {rod }}+\mathbf{M}_{\text {mass }} .
\end{aligned}
$$

The work $W$ done by the external point force excitation is

$$
W=\int_{0}^{L} F \delta\left(x-x_{f}\right) w\left(x_{f}\right) \mathrm{d} x
$$

where $F$ and $x_{f}$ denote the external disturbance force and its applied position and $\delta(x)$ is the Dirac delta function.

Finally, the system characteristic equation in a standard eigenvalue matrix form is derived

$$
\left(\mathbf{K}-\omega^{2} \mathbf{M}\right) \mathbf{A}=\mathbf{F}
$$

where $\mathbf{F}$ is the external force excitation vector for the forced vibration analysis, and the corresponding response coefficient vectors are

$$
\begin{aligned}
\mathbf{A} & =\left\{\begin{array}{llllll}
\mathbf{A}_{1} & \mathbf{A}_{2} & \cdots & \mathbf{A}_{8}
\end{array}\right\}^{T}, \\
\mathbf{A}_{i} & =\left\{\begin{array}{llllllll}
a_{0}^{i} & a_{1}^{i} & \cdots & a_{n}^{i} & b_{1}^{i} & b_{2}^{i} & b_{3}^{i} & b_{4}^{i}
\end{array}\right\}_{1 \times(N+5)},
\end{aligned}
$$

where $\mathbf{A}$ is the unknown Fourier series coefficient vector. By solving such a standard eigenvalue problem, the corresponding natural frequency and mode shape can be easily obtained.

Since the constructed admissible function is sufficiently smooth in the entire solving region, the various order spatial derivations of translational displacement function can be calculated in a straightforward way, namely, in terms of term-by-term operation. Power flow can be viewed as the time average of vibrational energy transfer across any section of beam structure. Power flow through per unit cross-sectional area of such propulsion shafting model shown in Figure 2 can be calculated as [30]

$$
P=\frac{1}{2} \operatorname{Re}\left\{Q\left(\frac{\partial w}{\partial t}\right)^{*}-M\left(\frac{\partial^{2} w}{\partial x \partial t}\right)^{*}\right\},
$$

in which $*$ denotes the complex conjugate, $\operatorname{Re}\{\}$ is the real part of a complex variable, and $Q$ and $M$ are the transverse shear force and bending moment in the beam structure, respectively. These two variables can be calculated through the corresponding spatial derivatives of beam displacement function, namely,

$$
\begin{aligned}
& M=E I \frac{\partial^{2} w}{\partial x^{2}} \\
& Q=-E I \frac{\partial^{3} w}{\partial x^{3}} .
\end{aligned}
$$

As mentioned above, the supposition of the standard Fourier series and auxiliary functions equation (3) can guarantee the sufficient continuity of various spatial derivatives in the entire solving domain, including the general elastic end and bearing supports. Power flow and structural intensity can be predicted through a straightforward postprocessing operation using the dynamic response vector $\mathbf{A}$ calculated from equation (19).

\section{Numerical Results and Discussions}

In this section, numerical examples will be presented to demonstrate the reliability and effectiveness of the proposed model for analyzing flexural vibration of propulsion shaft system with thrust force and distributed bearing supports. In the current model, arbitrary distribution of partially elastic support with variable stiffness and different thrust forces can be easily solved by just changing the corresponding description coefficients. For the elastic boundary condition, when the restraining stiffness is set as a medium number $(0 \sim+\infty)$, such elastic restraint can be then achieved. Any change of boundary condition, bearing support, thrust force, and variable cross section will need no much modification on the theoretical formulation and simulation code. Then, results of the original model are compared with other simplified models to illustrate the advantages of the proposed model. In the following study, thrust force will be zero if it is not mentioned specifically. Structural damping associated with the shafting system is taken into account in terms of complex Young's modulus $E=E(1+j \eta)$, in which the damping loss factor $\eta$ will be set as 0.001 .

\subsection{Vibration Characteristics of the Propulsion Shafting} System. Firstly, vibration characteristics of the propulsion shafting system are considered. Tabulated in Table 2 are the first ten frequencies of the original model under FreeClamped (F-C) and Free-Free (F-F) boundary conditions compared with those results calculated by using Finite Element Analysis in COMSOL, in which the restraining stiffness corresponding to the clamped boundary is set as $10^{12} \mathrm{~N} / \mathrm{m}$. It can be seen that these two results can agree very well with each other. The first two natural frequencies under F-F boundary conditions are similar due to the large mass effect of propeller. Figure 4 plots the first four dimensionless mode shapes under F-F and F-C boundary conditions which also coincide well with the results from COMSOL. In Figure 4, the displacement on the propeller side is nearly zero except for the first mode shape, which means the concentrated mass has significant influence on the higher order modes. The torque generated by main engine inputs from the right end of propulsion system whose displacement should be small. According to the mode shape results shown in Figure 4, the right end of the original model should be clamped, and the left side is free (Table 3).

In most of the existing studies, appropriate simplification is employed in vibration analysis of propulsion shafting system such as point support instead of the bearing support. In order to illustrate the difference and advantage of the current model comparing with the simplified model, four comparative common models are introduced and used in subsequent analysis:

Model A: on the basis of the original model, the variable cross section beam $\left(3^{\#}\right)$ is changed into a uniform beam with its diameter $500 \mathrm{~mm}$ the same as $2^{\#}$ beam member.

Model B: on the basis of the original model, $1^{\#}, 2^{\#}$, and $3^{\#}$ beam sections have the same diameter of $500 \mathrm{~mm}$ 
TABLE 2: The first ten modal frequencies of the original model with F-F and F-C boundary conditions.

\begin{tabular}{|c|c|c|c|c|c|c|}
\hline \multirow{3}{*}{ Mode order } & \multicolumn{6}{|c|}{ Boundary condition } \\
\hline & \multicolumn{3}{|c|}{ F-F } & \multicolumn{3}{|c|}{$\mathrm{F}-\mathrm{C}$} \\
\hline & Original model & COMSOL & Diff $(\%)$ & Original model & COMSOL & Diff $(\%)$ \\
\hline 1 & 15.341 & 15.342 & 0.005 & 15.381 & 15.38 & 0.003 \\
\hline 2 & 16.726 & 16.740 & 0.083 & 38.491 & 38.49 & 0.006 \\
\hline 3 & 39.398 & 39.442 & 0.111 & 60.027 & 60.027 & 0.001 \\
\hline 4 & 60.086 & 60.081 & 0.008 & 94.812 & 94.817 & 0.006 \\
\hline 5 & 92.209 & 92.20 & 0.01 & 124.975 & 124.94 & 0.028 \\
\hline 6 & 110.763 & 110.82 & 0.052 & 158.209 & 158.19 & 0.012 \\
\hline 7 & 152.492 & 152.51 & 0.012 & 227.067 & 227.05 & 0.007 \\
\hline 8 & 218.007 & 218.03 & 0.01 & 298.02 & 297.94 & 0.027 \\
\hline 9 & 285.114 & 285.15 & 0.013 & 386.86 & 386.79 & 0.018 \\
\hline 10 & 365.787 & 365.81 & 0.006 & 474.613 & 474.56 & 0.011 \\
\hline
\end{tabular}

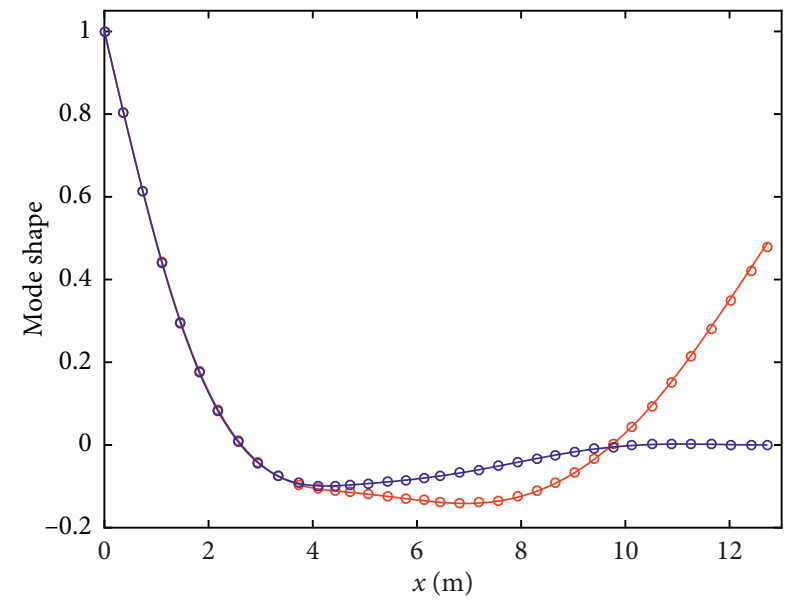

$\circ$ COMSOL result FF $\circ$ COMSOL result FC

- Present result FF_ Present result FC

(a)

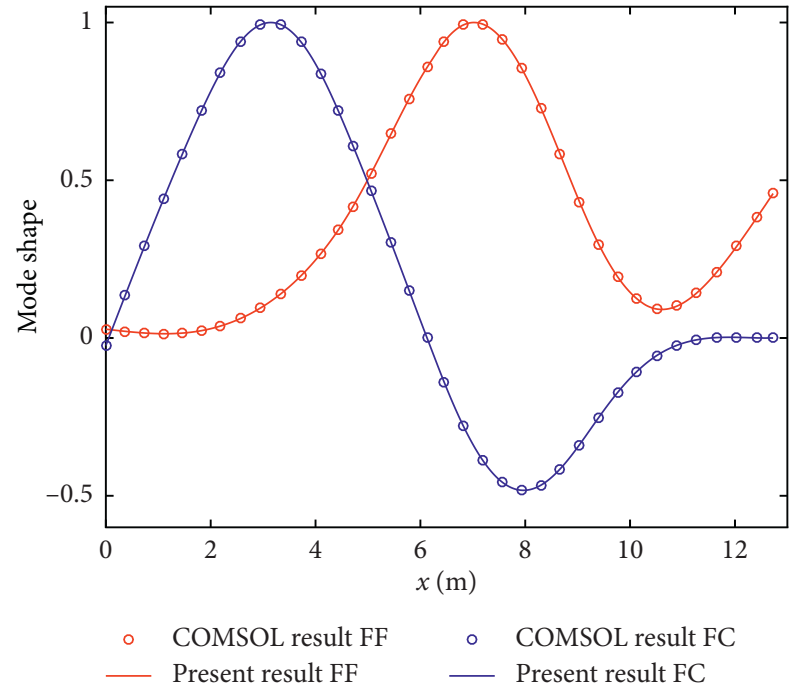

(c)

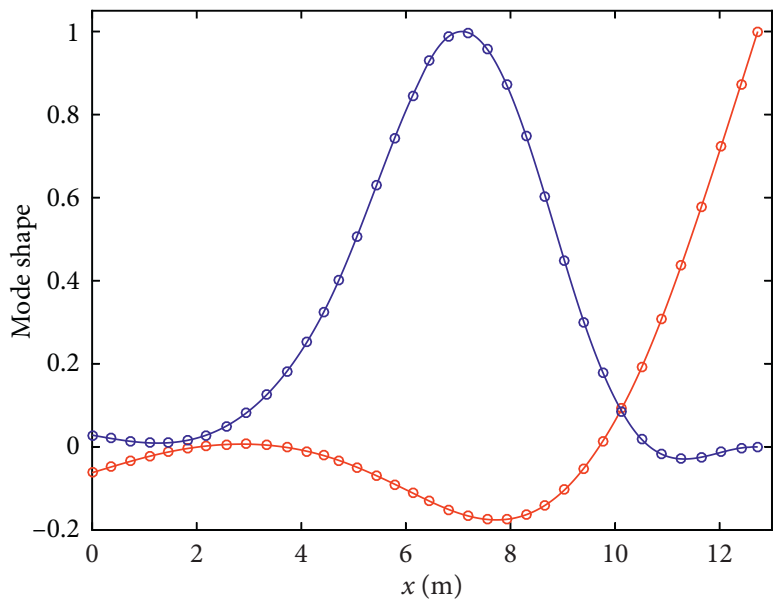

$\circ$ COMSOL result FF $\quad$ COMSOL result FC

Present result FF_ Present result FC

(b)

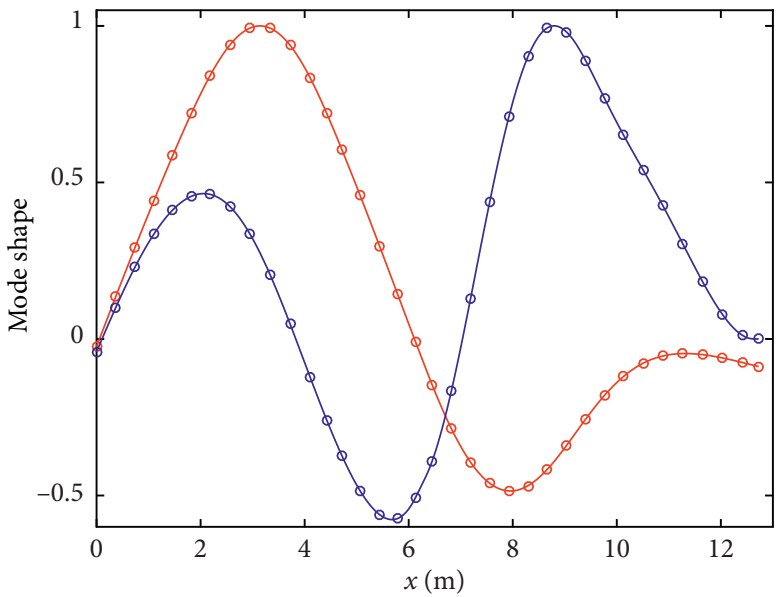

- COMSOL result FF $\quad$ COMSOL result FC

- Present result FF _ Present result FC

(d)

Figure 4: The first four mode shapes under F-F and F-C boundary conditions. (a) Mode shape 1. (b) Mode shape 2. (c) Mode shape 3. (d) Mode shape 4 . 
TABLE 3: Classification societies' standard for simplified point support position of rear stern bearing.

\begin{tabular}{lccc}
\hline Classification societies & Lignum vitae bearing & Lily gold bearing & Remarks \\
\hline BV & $(0.5 \sim 0.8) D$ & $0.5 D$ & \\
LR & $(1 / 4 \sim 1 / 3) L$ & $(1 / 3 \sim 1 / 2) L$ & $D$ is diameter, $L$ is length of bearing \\
NK & $D / 3, D / 2,4 D / 3, L / 5, L / 4, L / 5$ & $(1 / 7 \sim 1 / 3) L$ \\
CCS & $(1 / 4 \sim 1 / 3) L$ & \\
\hline
\end{tabular}

and $5^{\#}, 6^{\#}$, and $7^{\#}$ beam members have the same diameter of $390 \mathrm{~mm}$.

Model C: on the basis of the original model, point support takes place of the partial support located at the middle of all these three bearings with the same stiffness coefficients.

Model D: on the basis of the original model, the point support of the stern rear bearing located at the $1 / 3$ length of the bearing according to the standard of classification society and the other two bearings are still located at the middle of such bearing.

Vibrational characteristics of these comparative models can be easily achieved by adjusting the corresponding parameters in current modeling framework. Tables 4 and 5 present the first ten modal frequencies of these four comparative models comparing with original model under F-C boundary conditions. In Table 4, the appropriate differences of models A and B indicate that the proper simplification of shaft diameter is acceptable for the vibration characteristics analysis of such structure. However, the differences of models $\mathrm{C}$ and $\mathrm{D}$ for the first ten frequencies are larger, which demonstrates that the partial support cannot be replaced by point support in an accurate vibration analysis. In general, precise model is necessary for vibration analysis and current model of this work is suitable for the study of vibration characteristics of such propulsion shafting system.

\subsection{Influence of Various Model Parameters}

3.2.1. Influence of Boundary Conditions at Right End. According to Table 2, boundary condition has an important influence on the vibration characteristics of propulsion shafting system. The first ten modal frequencies of the original model under various elastic boundaries restrained at the right end are tabulated in Table 6. It can be observed that the fundamental frequency hardly changes along with the increase of stiffness because the mode shape under fundamental frequency is much larger than the right end according to Figure 4(a). As the propulsion shafting is an asymmetric structure, this value will increase in certain stiffness region from $10^{4}$ to $10^{8} \mathrm{~N} / \mathrm{m}$ irregularly for the higher modal frequencies. When the stiffness is $10^{10} \mathrm{~N} / \mathrm{m}$, the frequency will be equal to those under F-C boundary listed in Table 2.

3.2.2. Influence of Bearing Support Stiffness. For the propulsion shafting system, the ship navigation status can affect the inclination angle and bearing support condition. In this section, effect of various bearing support stiffnesses on the
TABle 4: The first ten natural frequencies of original model compared with models A and B under F-C boundary conditions.

\begin{tabular}{lccccc}
\hline $\begin{array}{l}\text { Mode } \\
\text { order }\end{array}$ & $\begin{array}{c}\text { Original } \\
\text { model }\end{array}$ & \multicolumn{2}{c}{ Model A } & \multicolumn{2}{c}{ Model B } \\
& Value & Value & $\begin{array}{c}\text { Diff } \\
(\%)\end{array}$ & Value & Diff (\%) \\
\hline 1 & 15.38 & 15.38 & 0 & 15.434 & 0.345 \\
2 & 38.491 & 38.007 & 1.257 & 37.710 & 2.030 \\
3 & 60.027 & 60.003 & 0.039 & 59.899 & 0.213 \\
4 & 94.812 & 95.937 & 1.179 & 96.929 & 2.225 \\
5 & 124.975 & 125.33 & 0.286 & 126.618 & 1.317 \\
6 & 158.209 & 158.825 & 0.386 & 158.959 & 0.470 \\
7 & 227.067 & 229.819 & 1.203 & 229.790 & 1.190 \\
8 & 298.02 & 299.124 & 0.37 & 298.099 & 0.042 \\
9 & 386.861 & 392.192 & 1.377 & 390.734 & 1.000 \\
10 & 474.613 & 475.743 & 0.236 & 475.303 & $0.143 \mathrm{~s}$ \\
\hline
\end{tabular}

TABle 5: The first ten natural frequencies of original model compared with models $\mathrm{C}$ and D under F-C boundary conditions.

\begin{tabular}{lccccc}
\hline $\begin{array}{l}\text { Mode } \\
\text { order }\end{array}$ & $\begin{array}{c}\text { Original } \\
\text { model }\end{array}$ & \multicolumn{2}{c}{ Model C } & \multicolumn{2}{c}{ Model D } \\
& Value & Value & $\begin{array}{c}\text { Diff } \\
(\%)\end{array}$ & Value & $\begin{array}{c}\text { Diff } \\
(\%)\end{array}$ \\
\hline 1 & 15.38 & 14.132 & 8.114 & 15.726 & 2.248 \\
2 & 38.491 & 41.681 & 8.288 & 41.477 & 7.757 \\
3 & 60.027 & 65.250 & 8.702 & 62.700 & 4.453 \\
4 & 94.812 & 99.720 & 5.168 & 99.945 & 5.405 \\
5 & 124.975 & 129.698 & 3.782 & 129.216 & 3.396 \\
6 & 158.209 & 159.668 & 0.918 & 160.211 & 1.262 \\
7 & 227.067 & 227.651 & 0.248 & 228.222 & 0.500 \\
8 & 298.02 & 301.183 & 1.077 & 302.002 & 1.352 \\
9 & 386.861 & 386.296 & 0.148 & 386.636 & 0.060 \\
10 & 474.613 & 471.945 & 0.565 & 471.788 & 0.598 \\
\hline
\end{tabular}

TABLE 6: The first ten natural frequencies of original model under various elastic boundary restraints at the right end.

\begin{tabular}{lccccc}
\hline \multirow{2}{*}{ Mode order } & \multicolumn{5}{c}{ Various elastic boundary restraints $(\mathrm{N} / \mathrm{m})$} \\
& $10^{2}$ & $10^{4}$ & $10^{6}$ & $10^{8}$ & $10^{10}$ \\
\hline 1 & 15.341 & 15.341 & 15.354 & 15.379 & 15.380 \\
2 & 16.705 & 16.706 & 17.327 & 36.637 & 38.469 \\
3 & 39.434 & 39.438 & 39.460 & 48.583 & 60.023 \\
4 & 60.083 & 60.086 & 60.079 & 60.159 & 94.699 \\
5 & 92.185 & 92.184 & 92.224 & 94.175 & 122.644 \\
6 & 110.754 & 110.786 & 110.880 & 120.903 & 156.495 \\
7 & 152.497 & 152.487 & 152.515 & 155.325 & 223.717 \\
8 & 217.997 & 218.004 & 218.042 & 221.557 & 291.042 \\
9 & 285.106 & 285.105 & 285.151 & 289.102 & 368.156 \\
10 & 365.7735 & 365.7764 & 365.8292 & 370.8595 & 446.9831 \\
\hline
\end{tabular}




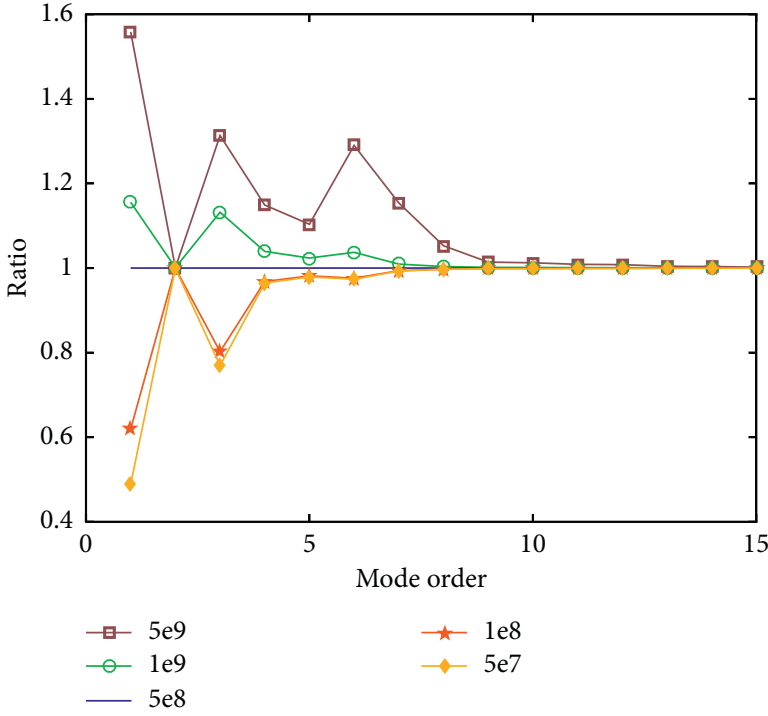

(a)

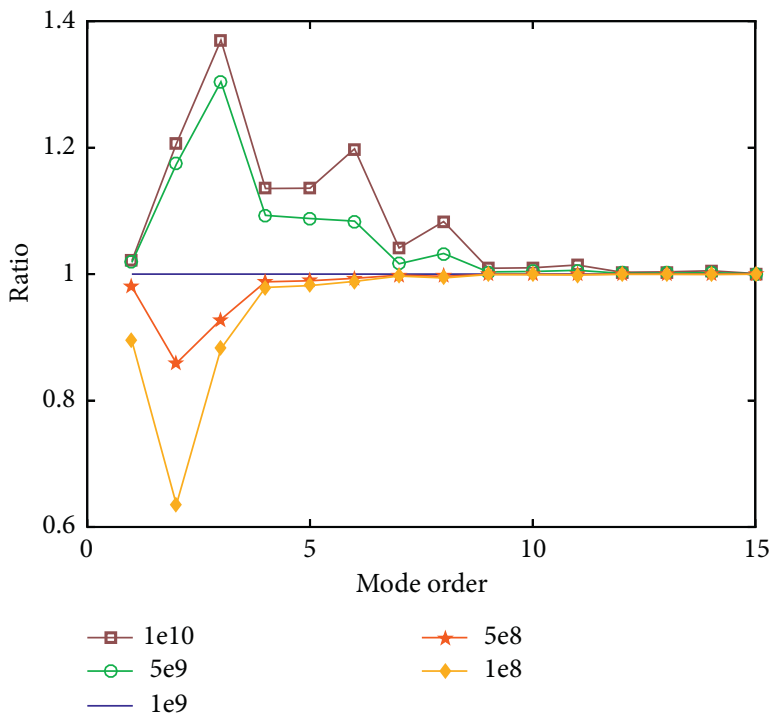

(b)

FIGURE 5: Influence of various bearing support stiffnesses on the modal frequencies under F-C boundary condition. (a) Stern rear bearing; (b) stern front bearing.

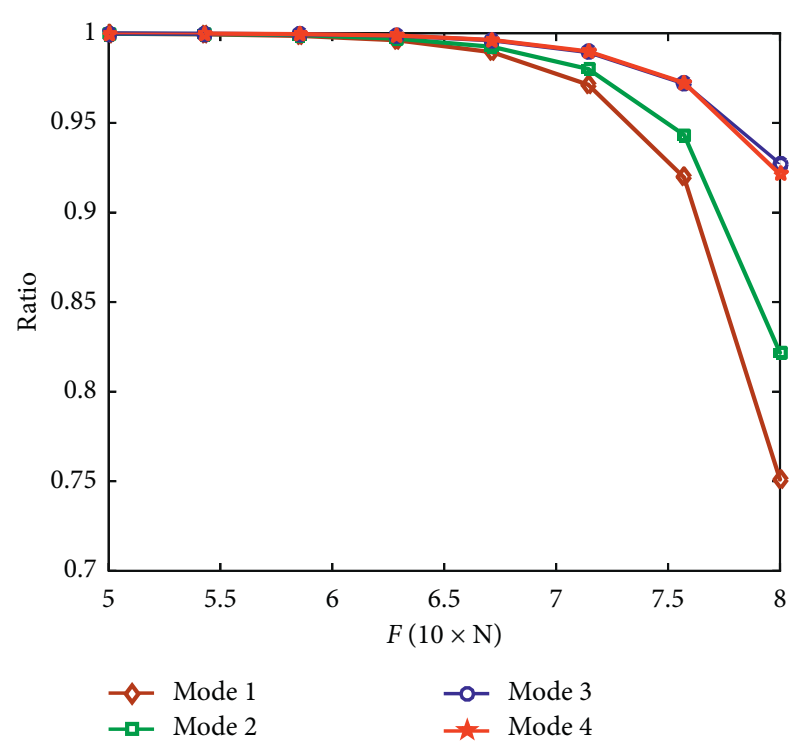

FIgURE 6: The first four natural frequencies under various thrust forces with F-C boundary conditions.

vibration characteristics of propulsion shafting system is performed. The ratio of natural frequencies calculated under various stiffnesses to those of the original model is shown in Figure 5. As we can see, when the supporting stiffness becomes much bigger, the frequency will increase, and the influence scope of bearings will become wider. The stiffness of stern rear bearing has great effect for the $1^{\text {st }}, 3^{\text {rd }}$, and $6^{\text {th }}$ mode frequencies and has little effect for the second frequency because the displacement at stern rear bearing in Figure 4(b) is nearly zero. Similarly, the stern front bearing also has great influence for the higher frequencies and has less impact on the fundamental modal frequency. In general, bearing supports at different positions will have distinct and different effects on the modal characteristics of such propulsion shafting system.

3.2.3. Influence of Various Thrust Forces. Thrust force generated by propeller is variable due to the fluctuation of shaft rotational speed and sea state. The differential governing equation of beam vibration shows that such thrust force applied on shafting structure can reduce the bending moment of the shafting, thus affecting the lateral vibration behavior of the shafting system [20]. Ratio of the first four modal frequencies calculated under various thrust forces to the result of original model is presented in Figure 6. The results show that the modal frequency will decrease while the thrust force increases. The larger thrust force has a much bigger effect for the lower modal parameters.

\subsection{Power flow Analysis of Propulsion Shafting System}

3.3.1. Results Validation. For the ship shafting system, the excitation force is generated by the propeller and the frequency $f_{S}$ is

$$
f_{s}=\frac{n z r}{60} \mathrm{~Hz}
$$

in which $r$ is the tones of propeller force $(r=1,2,3, \ldots$, namely, blade tone, double blade tone), $z$ is number of propeller blades, and $n$ is the propeller speed $(\mathrm{r} / \mathrm{min})$. According to the model parameters of this propulsion shafting system, the frequency of excitation force generated by propeller is $8 r \mathrm{~Hz}$. According to Table 2, the first natural frequency of propulsion shafting under F-C boundary condition is $15.38 \mathrm{~Hz}$ which is very close to $16 \mathrm{~Hz}$. Then, Figure 7 presents the comparison of current solution with those results of COMSOL, in which the frequency is $16 \mathrm{~Hz}$ 


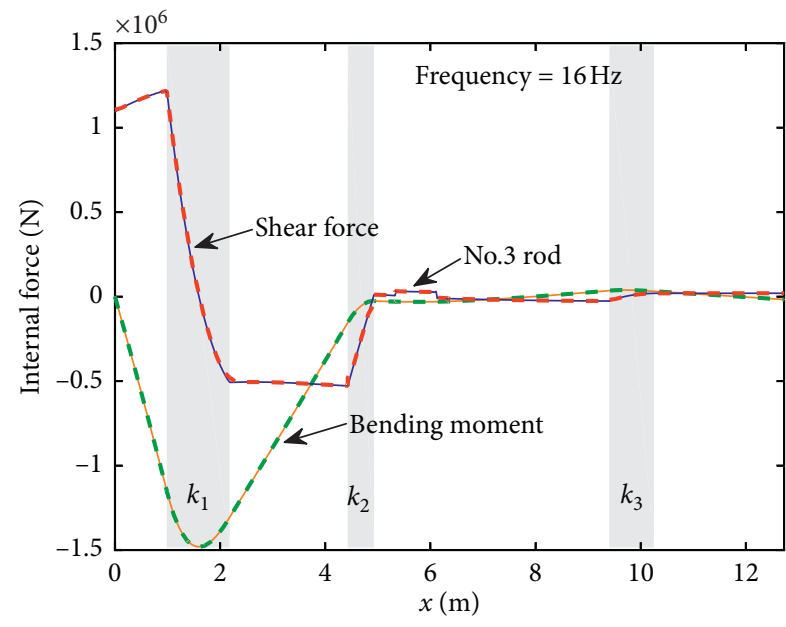

(a)

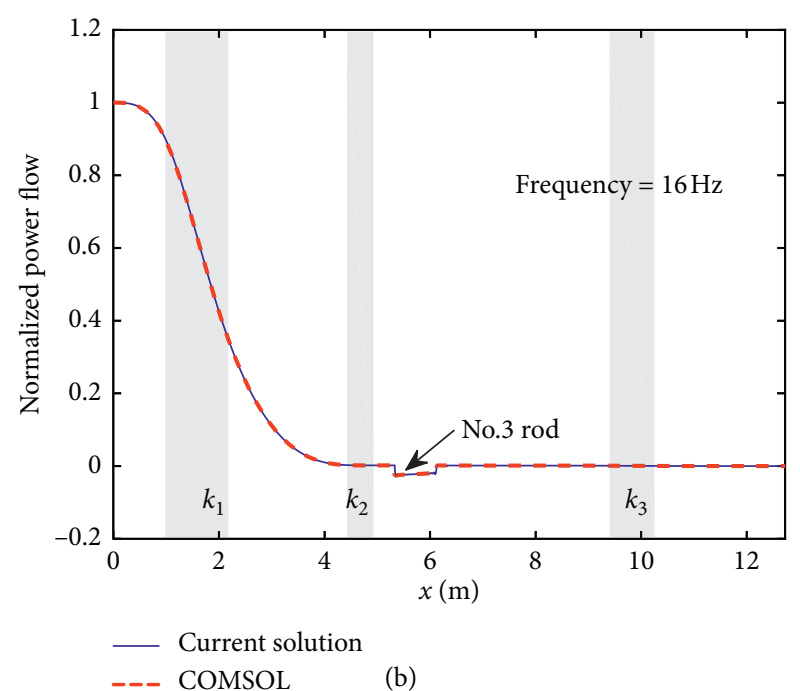

- - COMSOL

(b)

Figure 7: Comparison of power flow analysis made by current solution and COMSOL. (a) Internal force; (b) normalized power flow.

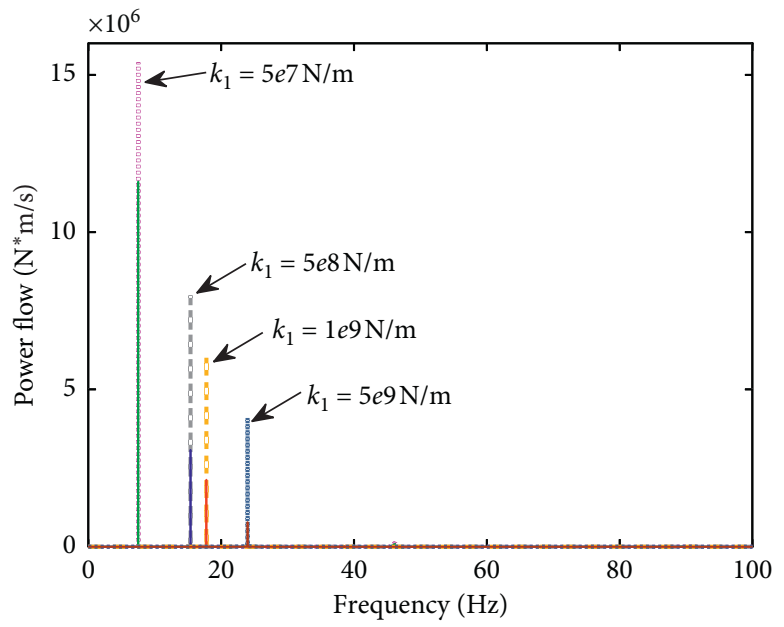

(a)

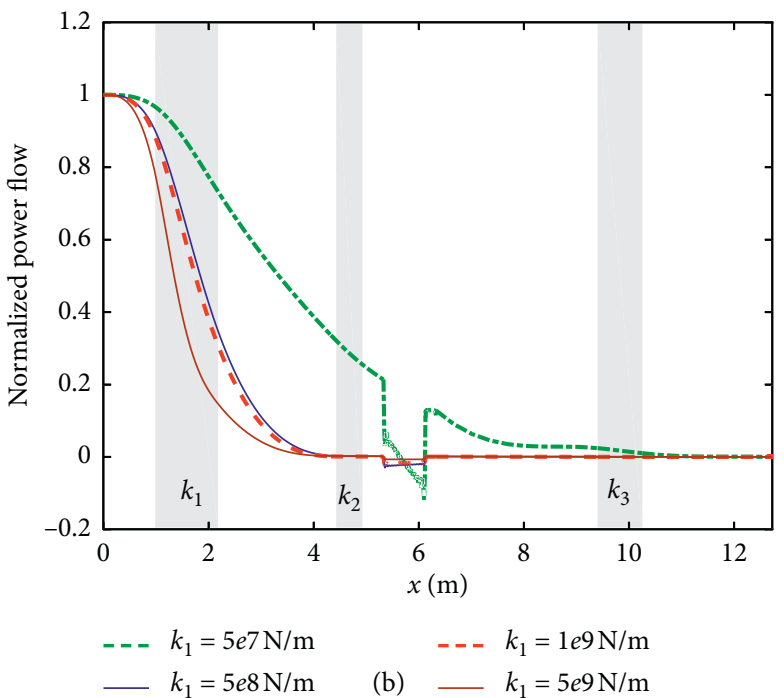

Figure 8: Power flow analysis of the propulsion system with different stiffnesses of stern rear bearing. (a) Power flow through bearing; (b) power flow distribution across the whole structure.

and the gray area is the location of three bearings of propulsion shafting. Solid and dashed lines represent the results of current solution and COMSOL, respectively. It is clear that both the integral force and power flow agree well with the results calculated from COMSOL. From Figure $7(a)$, one can observe that the abrupt changes will emerge at the location of bearings, which means the bearing support has great effect for the shear force. A small jump of shear force can be also found at the variable cross section area, which causes the same phenomenon in Figure 7(b). Power flow will decrease while transmitting through propulsion shafting system and most of the energy will dissipate by the damping effect of stern shaft. Moreover, stern rear bearing has a great effect for energy transmission as the curve of normalized power flow decreases greatly via stern rear bearing.

3.3.2. Influence of Stern Rear Bearing. According to Figure 7, the stern rear bearing can play an important role in vibrational energy transmission of propulsion shafting system. Power flow with different stiffness of stern rear bearing is discussed in Figure 8. Figure 8(a) presents the power flow through the stern rear bearing and the decline of energy transmission can be easily observed via the height difference between solid and dashed lines. Frequencies at resonant peaks are natural frequencies of the model and have significant difference while increasing stiffness of stern rear 


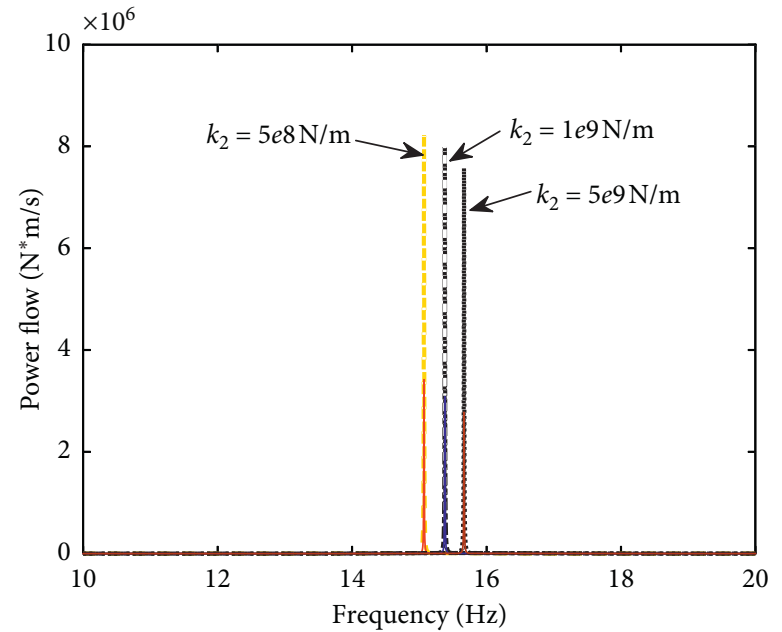

(a)

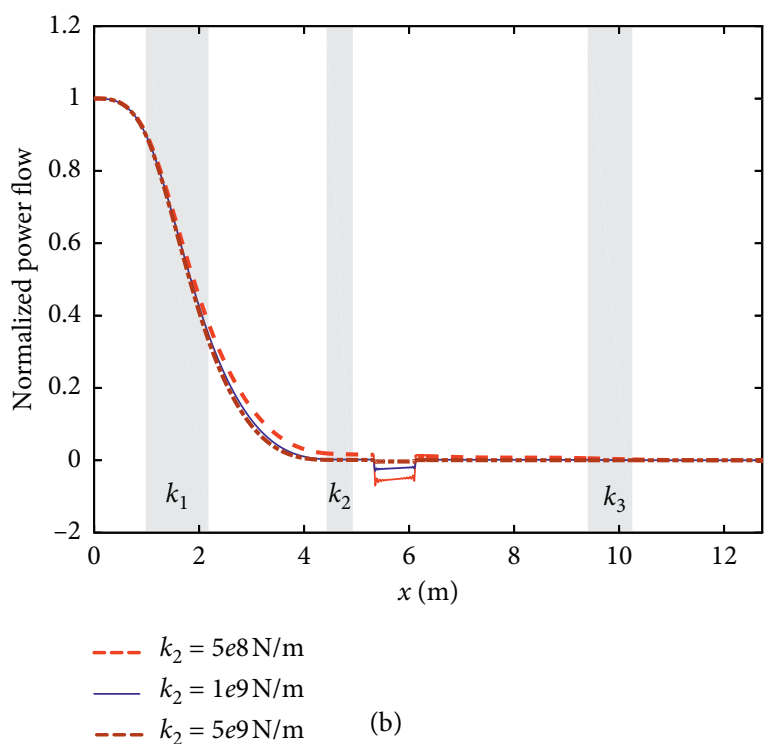

(b)

Figure 9: Power flow analysis of the propulsion system with different stiffnesses of stern front bearing. (a) Power flow through bearing; (b) power flow distribution across the whole structure.

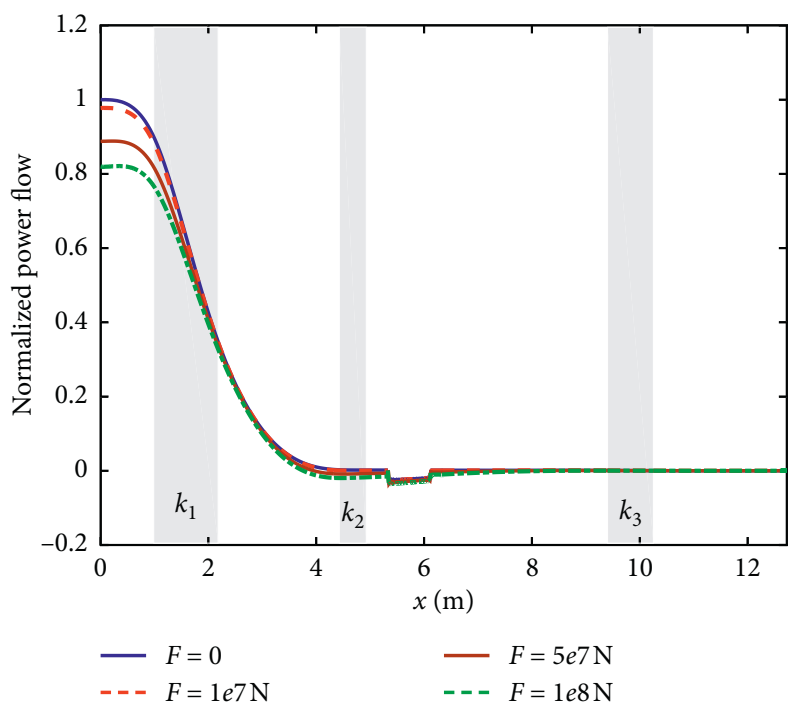

FIGURE 10: Power flow analysis of propulsion shafting system with different thrust forces.

bearing, which coincides with the results of Figure 5(a). The amplitude of power flow becomes smaller along with the increase of stern rear bearing stiffness and the reduction extent through the stern bearing is nearly the same. Plotted in Figure $8(\mathrm{~b})$ is the normalized power flow through the whole structure at the excitation frequency $16 \mathrm{~Hz}$, and it can be found that power flow will transmit to the stern front bearing for the smaller stiffness such as $5 \mathrm{e} 7 \mathrm{~N} / \mathrm{m}$, in which the decrease of $3^{\#}$ beam will become larger.

3.3.3. Influence of Stern Front Bearing. Similarly, power flow with different stiffnesses of stern front bearing is also discussed in Figure 9. The decline of power flow has barely change for various stiffnesses of stern front bearing. In Figure 9(a), frequencies corresponding to the peaks have less difference than the effect of stern rear bearing. The curves almost coincide with each other except for the location of variable cross section.

3.3.4. Influence of Thrust Force. In Section 3.2.3, the influence of thrust force on vibration characteristics is discussed. In order to analyze the effect of thrust force on energy transmission, Figure 10 shows the power flow transmission under different thrust forces. It can be found that the input power flow at the left end decreases along with increasing of thrust force. However, power flow after the 


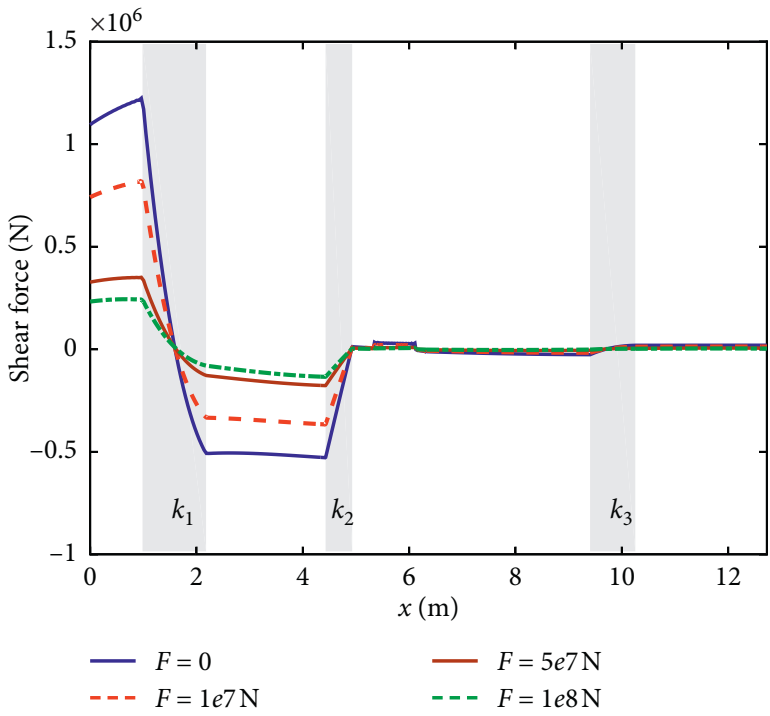

(a)

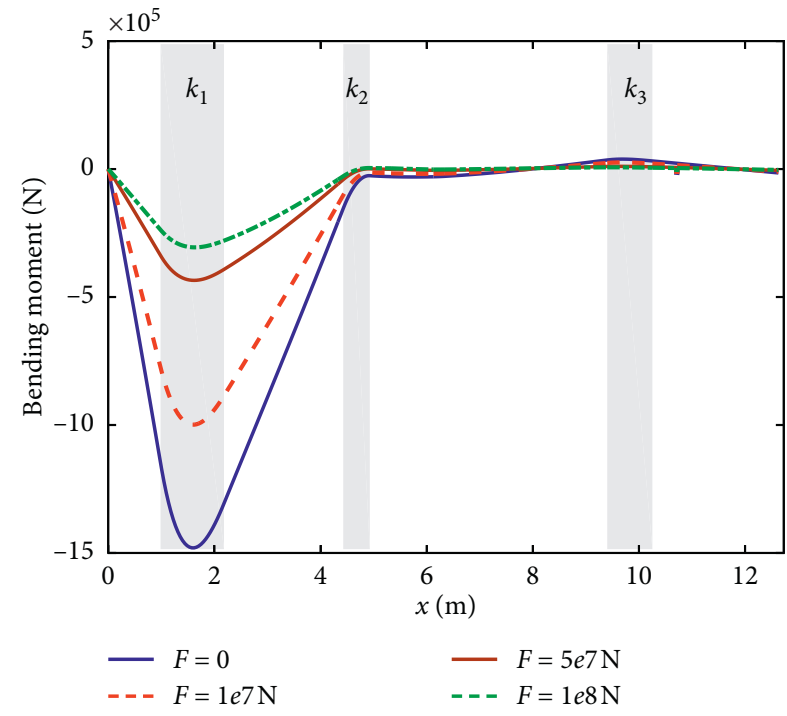

(b)

FIGURE 11: Internal force in propulsion shafting with various thrust forces. (a) Shear force; (b) bending moment.

stern rear bearing is nearly the same. In order to explain this phenomenon, Figure 11 plots the internal forces in propulsion shafting with various thrust forces. With the increase of thrust force, shear force at power input end and the peak of bending moment will decrease which illustrates that thrust force has important effect for the input power flow.

\section{Conclusions}

In this paper, a general dynamic analysis model for the study of transverse vibration characteristics and power flow behavior of a propulsion shafting system with thrust force and spatial bearing support conditions is established for the first time, in which energy principle description in conjunction with Rayleigh-Ritz procedure is employed. With the aim to make admissible function sufficiently smooth in the whole beam members, a superposition of Fourier series and boundary smoothed auxiliary polynomials is constructed for the displacement function expression. Potential energy of the stepped beams with thrust force and spatial bearing supports is formulated in system Lagrangian, which allows the analysis of current model through the minimization with respect to all the unknown coefficients.

Numerical examples are then given to validate the proposed model and study the vibration characteristics and dynamic behavior of propulsion shafting with various thrust forces and spatial bearing supports. Results show that the current model can make an accurate prediction of modal characteristics of such propulsion shafting structure, and the thrust force and spatial bearing have significant influence on vibration characteristics and energy transmission in such complicated structure. Moreover, effects of thrust force and spatial bearing supports will become weaker for the higher mode. Power flow analysis shows that the stiffness of stern bearing has much greater effect for the vibrational energy transmission pattern than the front bearing, and thrust force has important effect for the shear force at power input end and the peak of bending moment. This work can shed some new lights on the systematic understanding of dynamic behavior of propulsion shafting structure with complex boundary and general bearing supports.

\section{Data Availability}

The data are available on request.

\section{Conflicts of Interest}

The authors declare that they have no conflicts of interest.

\section{Acknowledgments}

This work was supported by the National Natural Science Foundation of China (Grant no. 11972125) and Fok Ying Tung Education Foundation (Grant no. 161049).

\section{References}

[1] R. Warikoo and M. R. Haddara, "Analysis of propeller shaft transverse vibrations," Marine Structures, vol. 5, no. 4, pp. 255-279, 1992.

[2] X. P. Yan, Z. X. Li, C. Q. Yuan, H. H. Zhu, and Z. L. Liu, "Modelling and control of marine propulsion system coupled with hull deformation," Ship and Ocean Engineering, vol. 40, no. 1, pp. 60-63, 2011.

[3] Y. Hori and M. Tanaka, "Lateral vibration of propeller shaft systems," Bulletin of Marine Engineering Society in Japan, vol. 14, pp. 338-344, 1978.

[4] S. Hylarides, "Transverse vibrations of ship's propulsion systems1," International Shipbuilding Progress, vol. 22, no. 252, pp. 275-288, 1975.

[5] M. R. Haddara, "On the transverse vibration of a propeller-tail shaft system," Ocean Engineering, vol. 15, no. 2, pp. 119-126, 1988. 
[6] J. C. Zhu, H. H. Zhu, X. P. Yan, and P. Jiang, "A research on the influence of vessel-propeller coupling effect to shaft's lateral vibration," Applied Mechanics and Materials, vol. 226-228, pp. 106-112, 2012.

[7] S. Naguleswaran, "Transverse vibration of an Euler-Bernoulli uniform beam on up to five resilient supports including ends," Journal of Sound and Vibration, vol. 261, no. 2, pp. 372-384, 2003.

[8] H.-Y. Lin, "Dynamic analysis of a multi-span uniform beam carrying a number of various concentrated elements," Journal of Sound and Vibration, vol. 309, no. 1-2, pp. 262-275, 2008.

[9] L. Murawski and A. Charchalis, "Simplified method of torsional vibration calculation of marine power transmission system," Marine Structures, vol. 39, pp. 335-349, 2014.

[10] H. Han, K. Lee, S. H. Jeon, and S. Park, "Lateral-torsional coupled vibration of a propulsion shaft with a diesel engine supported by a resilient mount," Journal of Mechanical Science and Technology, vol. 31, no. 8, pp. 3727-3735, 2017.

[11] Q. Huang, Y. Yan, C. Wang, Y. Zhang, and Y. Jin, "Numerical and experimental analysis of coupled transverse and longitudinal vibration of a marine propulsion shaft," Journal of Mechanical Science and Technology, vol. 30, no. 12, pp. 5405-5412, 2016.

[12] G. F. Safina, "Analysis of direct and inverse problems on transverse vibrations of a supported shaft," Russian Journal of Nondestructive Testing, vol. 46, no. 4, pp. 302-313, 2010.

[13] J.-u. Lee, B. Jeong, and T.-H. An, "Investigation on effective support point of single stern tube bearing for marine propulsion shaft alignment," Marine Structures, vol. 64, pp. 1-17, 2019.

[14] M. Eisenberger, D. Z. Yankelevsky, and M. A. Adin, "Vibrations of beams fully or partially supported on elastic foundations," Earthquake Engineering \& Structural Dynamics, vol. 13, no. 5, pp. 651-660, 1985.

[15] G. A. Kushner, V. A. Mamontov, and A. A. Khalyavkin, "Mechanics of contact interaction between propeller shaft and stern bearing under the transverse vibrations," Herald of Dagestan State Technical University. Technical Sciences, vol. 44, no. 2, pp. 28-36, 2017.

[16] S. E. Motaghian, M. Mofid, and P. Alanjari, "Exact solution to free vibration of beams partially supported by an elastic foundation," Scientia Iranica, vol. 18, no. 4, pp. 861-866, 2011.

[17] J.-S. Wu and B.-H. Chang, "Free vibration of axial-loaded multi-step Timoshenko beam carrying arbitrary concentrated elements using continuous-mass transfer matrix method," European Journal of Mechanics-A/Solids, vol. 38, pp. 20-37, 2013.

[18] S.-M. Kim, "Vibration and stability of axial loaded beams on elastic foundation under moving harmonic loads," Engineering Structures, vol. 26, no. 1, pp. 95-105, 2004.

[19] F. Borbón and D. Ambrosini, "On free vibration analysis of thin-walled beams axially loaded," Thin-Walled Structures, vol. 48, pp. 915-920, 2010.

[20] X. F. Li, A. Y. Tang, and L. Y. Xi, "Vibration of a Rayleigh cantilever beam with axial force and tip mass," Journal of Constructional Steel Research, vol. 80, pp. 15-22, 2013.

[21] S. Merz, R. Kinns, and N. Kessissoglou, "Structural and acoustic responses of a submarine hull due to propeller forces," Journal of Sound and Vibration, vol. 325, no. 1-2, pp. 266-286, 2009.

[22] J.-H. Song, S.-Y. Hong, Y. Kang, and H.-G. Kil, "Vibrational energy flow analysis of penetration beam-plate coupled structures," Journal of Mechanical Science and Technology, vol. 25, no. 3, pp. 567-576, 2011.
[23] J. X. Gao and L. Cheng, "Modeling and control of power flow in a double-beam system," Thin-Walled Structures, vol. 43, no. 5, pp. 751-771, 2005.

[24] G. P. Feng, Z. Y. Zhang, Y. Chen, and H. X. Hua, "Research on transmission paths of a coupled beam-cylindrical shell system by power flow analysis," Journal of Mechanical Science and Technology, vol. 23, no. 8, pp. 2138-2148, 2009.

[25] P. G. Dylejko, N. J. Kessissoglou, Y. Tso, and C. J. Norwood, "Optimisation of a resonance changer to minimise the vibration transmission in marine vessels," Journal of Sound and Vibration, vol. 300, no. 1-2, pp. 101-116, 2007.

[26] D. S. Xu, J. T. Du, and A. G. Liu, "An accurate and efficient series solution for the longitudinal vibration of elastically restrained rods with arbitrarily variable cross sections," Journal of Low Frequency Noise, Vibration and Active Control, vol. 38, no. 2, pp. 403-414, 2019.

[27] L. Chen, D. Xu, J. Du, and C. Zhong, "Flexural vibration analysis of nonuniform double-beam system with general boundary and coupling conditions," Shock and Vibration, vol. 2018, Article ID 5103174, 8 pages, 2018.

[28] S. Rao, Vibration of Continuous Systems, John Wiley \& Sons, Hoboken, NJ, USA, 2007.

[29] E. Farzad and R. B. Mohammad, "Longitudinal varying elastic foundation effects on vibration behavior of axially graded nanobeams via nonlocal strain gradient elasticity theory," Mechanics of Advanced Materials and Structures, vol. 25, no. 11, pp. 953-963, 2018.

[30] C. Liu, F. Li, and W. Huang, "Active vibration control of finite L-shaped beam with travelling wave approach," Acta Mechanica Solida Sinica, vol. 23, no. 5, pp. 377-385, 2010. 